getically the treatment can only be satisfactory when their combined or reciprocal motion is balanced about their common centre of gravity.

Centres of gravity, however, presumably disappear from relativity; and, what is more serious, so does the conservation of energy. For if there is nothing absolute about speed there can be nothing absolute about kinetic energy. The relativity expression for kinetic energy contains an arbitrary constant; and whether energy is conserved or not becomes a matter of convenience and definition. 'The claim that relativity pressed to extremes does away with all conservation, as hitherto understood in physics, has been seriously made by the eminent mathematician, Prof. Hilbert, of Göttingen. On the other hand, it might be replied, according to Sir Joseph Larmor, that kinetic energy has always been treated as relative to some other body on which work might conceivably be done, and that the really invariant quantity is not energy, but the integral of energy with time, called "action"; or as it may be regarded, perhaps preferably for some purposes, $i$ times angular momentum. ${ }^{2}$ For this appears to be independent of frames of reference--which energy certainly is not.

Acceptance of the theory of relativity correlates results, but does not explain them. The 2 which, by the way, is very suggestive of a constitutional gyrostatic ather structure. theory does not even seek to explain or account for phenomena: they just are so. It is not a dynamical theory, it is a method of arriving at results, like the second law of thermodynamics and the conservation of energy. The full dynamical explanation remains to be worked out, and it may turn out to be on very much the old lines along which we had previously regarded physical phenomena. The true relation between æther and matter, and how their interaction generates and affects light, is an immense subject, not in the least exhausted, and barely encroached upon, by the perception that certain consequences inevitably follow from an admission that the velocity of light is a critical limiting velocity, which cannot be exceeded, and which when compounded with any other velocity retains its old value.

Whether the properties of the rether can ever be formulated in terms of the same sort of dynamics as we have found so fruitful and effective in dealing with matter is at present an open question. Quite possibly a different dynamics may be needed, one perhaps of which we have as yet no conception; but let us not shut the door on discovery, assume that nothing of the sort can ever be arrived at, and think that pure mathematical abstractions, glorified and complicated sufficiently, can be an ultimate embodiment of physical laws or can adequately express the facts of Nature.

(To be continued.)

\title{
The Conference of the International Union against Tuberculosis.
}

$\mathrm{T}$ HOSE who have followed the course of tuberculosis in this country have noted that during the years of the war there was a sudden interruption in the fall of the curves illustrating case-rate and death-rate from that disease. Our work was then in fields abroad. Now, however, that we are getting back to pre-war conditions, peoples and nations are again joining forces in a new campaign against tuberculosis in our civil populations, and at the recent conference in London of the International Union against Tuberculosis delegates from forty nations, including China, Japan, Persia, and Czecho-Slovakia, met to discuss the great question of the cure and prevention of tuberculosis. Science knows no national borders, and it is obvious that the union is anxious to work with men from all nations, and to this end has drawn up a series of tentative regulations in order that when German physicians have composed the differences amongst themselves arrangements may be made for their reception into the councils of the union. The secretary of the old International Association against Tuberculosis appears to have assumed that everything would go on as before, and somewhat injudiciously made an attempt to call the old association together as a rival to the conference of the union of Allies and neutrals held in Paris last year. The wiser amongst his countrymen No. 2702 , vOL. [OT] were against this, and at present the German physicians are divided into two camps. For the present the International Union is content to make good its own footing, go its own way, and lay down its own lines of operations, at the same time leaving the regulations so elastic that as asperities are smoothed down and diffculties removed German workers may come in and take their part in its great work; and it is hoped that steps towards this will have been taken when the meeting is held in Brussels next year, or, at any rate, in Washington two years later. By that time the League of Nations may have got under way, and the international character of the union may have become complete.

At the opening sitting of the London meeting the Foreign Secretary, Lord Curzon, and the Minister of Health, Sir Alfred Mond, blessed in no uncertain terms the ideals and work of the union, and their presence no less than their works may be accepted as of good omen that the Government authorities will, in their anti-waste difficulties, remember that a penny wise Health Ministry may be pound foolish where the public health is concerned, and that the same holds good as regards the Board of Education.

Prof. Calmette, in a most interesting opening address characterised by all the clearness of vision and beauty of expression for which this French savant is noted, outlined a new hypothesis 
as to the importance of tuberculosis "carriers"i.e. centres of infection, themselves healthy to all intents and purposes. He claims (though the claim is not universally admitted) that von Pirquet's method of diagnosis is sufficiently characteristic to allow of a decision as to whether a patient is the subject of bacillary infection, or, in other words, capable of reacting to tuberculin as a result of the presence in the patient of a sensitising substance derived from the tubercle bacillus. Prof. Calmette holds, moreover, that by means of this reaction it is possible to work on a grand scale and to determine whether peoples and tribes, infants and adults, are infected by, or free from, tuberculosis. He quotes Col. Cummins and others to the effect that among African tribes about the equator where civilisation has not yet penetrated, and among the nomadic tribes of Arabs and Berbers, tuberculous infection is non-existent, or very rare, whilst in Natal, among the Zulus in the Transvaal, and in Madagascar, as also in the larger cities of North Africa, it is very prevalent. Those living in huts and native villages are, however, gradually becoming infected by contact with men from without. In the hinterland of the Cameroons from 3 to 6 per cent. only of adults are yet affected, whilst many aboriginal tribes are still quite free.

In civilised countries, although the reported percentage of tuberculous infection is comparatively high, a careful examination by the von Pirquet test and an examination of patients who die from other diseases would, Prof. Calmette claims, indicate the infection by the tubercle bacillus of many who, as yet, show no signs of tuberculous disease, and he believes that in the overcrowded cities of Europe and the United States few escape tuberculous infection, although the chances of death from tuberculosis are little more than one in eight. In the country districts the figures are not so high. Amongst the Kalmucks, even where the inhabitants have little intercourse with towns, 69.4 per cent. of the men and 30.6 per cent. of the women give a positive tuberculin reaction, whilst on the outskirts of the same territory, where commercial relations with the Russian population are very close, 95.7 per cent. of male adults and 88.5 per cent. of women give a positive reaction. Moreover, where differences occur, these are due very largely to the fact that tuberculous infection has been implanted in certain races over a longer or shorter period of time, although infections are also variable, being rare and slight or frequent and massive according to the particular mode of life of the people. Those who have been longest protected by virtue of their isolation from contact with the tuberculous prove to be most susceptible, aboriginal tribes and infants being the virgin soil on which the tubercle bacillus flourishes most luxuriantly. In the races that have been contaminated for centuries and exposed from infancy the disease assumes a chronic, slowly progressing form; but almost all become inNO. 2702 , VOL. IO 7$]$ fected. He finds evidence in support of his contention in the susceptibility of the bovine species to tuberculosis in the domesticated condition, although the wild cattle of Madagascar and of the pampas of the Argentine are said to be free from this disease. (It was found by the Royal Commission on Tuberculosis that Jersey cattle, though free from tuberculosis in the island, were readily infected when brought over to this country.)

Prof. Calmette is of opinion that the spread of human tuberculous infection throughout the world is due entirely to disseminators of virulent bacilli, most frequently through persons suffering from phthisis, who scatter enormous numbers of bacilli in their sputum and intestinal excretions either directly or by means of objects soiled by them, or again through the agency of living carriers, such as fiies. These open tuberculous cases are not the only factors in the dissemination of the disease. Many apparently healthy individuals suffering from latent or concealed tuberculous lesions which can be detected only by the tuberculin reaction are a source of danger in that they eliminate bacilli intermittently in their glandular or intestinal excretions, thus spreading infection in their environment.

E. C. Schroeder and W. E. Cotton found that 40 per cent. of cows giving a positive tuberculin reaction and showing no clinically demonstrable lesion discharged bacilli intermittently in their excreta, and that swine fed on these excreta easily became infected.

Similar observations were made by the Royal Commission on Tuberculosis, which, injecting tubercle bacilli into the circulating blood of healthy cattle, demonstrated their early appearance in the milk, whilst Calmette and Guérin showed that some of the bacilli injected into the blood-stream are eliminated through the bile passages. Lydia Rabinowitsch and Kempner, Tirze, with others in Germany, and Sheridan Delépine in England, have made similar observations with regard to the mammary glands of cattle. More recently it has been claimed by several observers that bacilli may often be found in the milk of tuberculous human mothers, even when the disease is in its early stages, or where only lymphatic glandular lesions are present. Prof. Calmette suggests that in the children of these mothers serious forms of tuberculosis are set up by slight but oft-repeated infections through breast-feeding or through prolonged or numerous accidental contacts with intermittent disseminators of bacilli. He goes further, and holds that when tuberculosis appears in environments where it has hitherto been absent it may have been introduced by a bacillus-carrier unrecognised because apparently healthy, which nevertheless has spread virulent germs either in excretions or through glandular secretions-e.g. milk in the case of lactating women; also that the disease in these more recently contaminated countries is more serious and more rapidly progressive than in the countries longer infected, and that it then assumes the form met with in young children rather than that met 
with in adults. He argues from all this that in dividuals with occult tuberculosis-the so-called healthy carriers of tubercle bacilli-are largely responsible for the spread of tuberculosis, not only amongst aboriginal and hitherto isolated peoples, but also amongst infants. He claims that this recently acquired knowledge of an unexpected danger makes the organisation of social defence against tuberculosis more difficult than when prophylaxis had to be based only on the education and isolation of phthisical patients, though he concedes that these are the principal disseminators of the disease. New peoples and infants should, wherever possible, be protected through a system of detection based both upon the judicious use of tuberculin tests and upon clinical examinations of the glandular system mainly by means of radioscopy.

It was interesting to find that Dr. Eric Pritchard, working along these lines during a period of ten years, had passed through his hands some thirty children who, by a process of injection with Koch's original tuberculin extending over five months, first in minute doses, to which they reacted, gradually increased up to I mg., to which the reaction was no more marked, could be immunised against any infection they were likely to be exposed to in the course of their lives. No accident such as might have been anticipated had occurred, and he was very hopeful that they had passed over that susceptible period of which Prof. Calmette had spoken.

It was felt by some who heard Prof. Calmette that his hypothesis, unless more fully explained, might lead to great misconception on the part of the public and be advanced as a reasonable excuse for inaction. If any apparently healthy person may be a "carrier"- and all may be infected in infancy-what good are elaborate precautions against tuberculous infection? The various public authorities might feel justified (and some might wish this) to sit with folded arms and tightly buttoned pockets. Later Prof. Calmette made it clear that his reference was only to those who had not hitherto been brought into contact with tuberculous patients; such as native races and infants, and that in civilised tuberculous communities other factors, surroundings, conditions of life, sources of infection, etc., must all receive due consideration. It was insisted that much information on these points had already been accumulated, and that the time had undoubtedly arrived when the aid of legislation should be called in for the prevention of tuberculosis. Two great sources of infection, human and bovine -expectorations from the former, and milk from the latter-containing massive doses of tubercle bacilli, must still be dealt with, and dealt with effectively. No measure conducing to the removal of mass infection should be neglected. Panic or phthisiophobia may well be discouraged when we learn from Sir George Newman that in seventythree years, since 1847 , when the death-rate from tuberculosis was 3 I 89 persons per million living, there has been a fall of 74 per cent., the standard death-rate from phthisis in this country in 1920 being 842 per million living. In other countries the decline, though not so marked, is still very substantial.

One feature was very prominent throughout the whole of the discussions. Although the search for prophylactic aids should not be discontinued, it must be recognised that the processes involved in tuberculosis are of a type different from those involved in most of the acute infective diseases, such as typhoid, plague, and the like, and, accepting this, we must follow Sir George Newman in his advice that "there is no beaten track in the further conquest of tuberculosis"; "the healthy child and the adult must be protected from massive, frequent, and prolonged infection"; "the powers of resistance of the patient must be fortified." "Freedom of thought, wide and deep research, and mobility of action will be necessary. Of much are we still in doubt, but of three things we may be certain. Only by surveying the complex problem, as a whole, in the spirit of preventive medicine, and co-ordinating the respective factors concerned, only by thorough, constructive, and intensive practice of our principles and by searching and finding the hidden secrets of immunisation, shall we at last conquer this disease."

\section{The Progress of British Forestry.}

THE First Annual Report of the Forestry Commissioners (H.M. Stationery Office, I92 I, $9 d$. net) deals with the period ended September 30 , 1920 , since which date a whole planting season has intervened; but a preliminary note gives information of the progress made to date. The Forestry Commissioners are now in actual possession of I03, IOo acres of land, of which 68 , 100 acres are classed as plantable with timber trees. The planting operations of the season I $920-2$ I have been successful, and the total area of new plantations is now about 8000 acres, while the stock of young trees in the nurseries is suffiํo. 2702 , VOL. 107$]$ cient to plant next season a largely increased area.

The Report opens with a sketch of the history of forestry in the United Kingdom, showing the stages which led to the passing of the Forestry Act in 1919. State forestry is a new departure in this country, and this part of the Report will instruct the public in the significance of a national forest policy. In the first period-that of destruction of the original forests, which lasted in some districts up to 1750 - great clearances were made for agriculture, sheep pasture, and the smelting of iron-ore. In the next period-that of private 